\title{
Educação ambiental no Parque Municipal Victório Siquierolli: elaboração, desenvolvimento e avaliação de um plano pedagógico
}

Eduardo Calixto Soares', Melina Santos Galdiano², Isabela Pacheco Borges³, Déborah Fernanda da Cunha Pereira ${ }^{4}$

\begin{abstract}
Resumo
Unidades de Conservação (UCs) são áreas destinadas à proteção de ecossistemas significativos, onde é comum o desenvolvimento de atividades e planos pedagógicos relacionados à Educação Ambiental (EA). O objetivo do trabalho foi a elaboração, o desenvolvimento e a avaliação de um plano pedagógico para uma UC localizada no Parque Municipal Victório Siquierolli, em Uberlândia, Minas Gerais, com o intuito de aprimorar o processo de ensino-aprendizagem de alunos de uma escola estadual do município com relação à conservação do meio ambiente e dos recursos naturais. Foram aplicados questionários e, posteriormente, um plano foi elaborado e testado com alunos de $9^{\circ}$ ano. Observou-se que o plano elaborado e as expectativas apresentadas pelos alunos foram atingidos. A partir da criação desse plano, os alunos foram capazes de assimilar várias informações sobre as questões ambientais, mostrando que a aplicação do plano como instrumento de EA, é viável.
\end{abstract}

\section{Palavras-chave}

Unidade de Conservação. Núcleo de Educação Ambiental. Métodos Didáticos.

1. Doutorando em Entomologia na Universidade de São Paulo, Brasil. E-mail: calixtos.edu@gmail.com.

2. Mestre em Ecologia e Conservação de Recursos Naturais pela Universidade Federal de Uberlândia, Minas Gerais, Brasil. E-mail: melinagaldiano@gmail.com.

3. Mestranda em Genética e Bioquímica na Universidade Federal de Uberlândia, Minas Gerais, Brasil. E-mail: isabela.pborges@gmail.com.

4. Doutoranda em Genética e Bioquímica na Universidade Federal de Uberlândia, Minas Gerais, Brasil. E-mail: deborahcp@gmail.com. 


\title{
Environmental education at Victório Siquierolli Municipal \\ Park: elaboration, development and evaluation of a pedagogical plan
}

Eduardo Calixto Soares*, Melina Santos Galdiano**, Isabela Pacheco Borges ${ }^{* * *}$, Déborah Fernanda da Cunha Pereira****

\begin{abstract}
Conservation Units are areas for protection of significant ecosystems, where it is common to develop activities and pedagogical plans related to Environmental Education. The aim of the work was the elaboration, development and evaluation of a pedagogical plan for a conservation unit located at Victório Siquierolli Municipal Park, Uberlândia, State of Minas Gerais, Brazil, with the purpose of improving the teaching-learning process of students in relation to the conservation of the environment and natural resources. Questionnaires were applied and, later, the pedagogical plan was elaborated and tested with 9th grade students. It was observed that the plan elaborated and the expectations presented by the students were achieved. From the creation of this plan, the students have assimilated several informations about environmental issues, showing that the application of the pedagogical plan as an Environmental Education instrument is feasible.
\end{abstract}

\section{Keywords}

Conservation Units. Environment Education Nucleus. Didactic Methods.

\footnotetext{
* PhD student in Entomology, University of São Paulo, State of São Paulo, Brazil. E-mail: calixtos.edu@gmail.com.

** Master in Ecology and Conservation of Natural Resources, Federal University of Uberlândia, State of Minas Gerais, Brazil. E-mail: melinagaldiano@gmail.com.

*** Master degree student in Genetics and Biochemistry, Federal University of Uberlândia, State of Minas Gerais, Brazil. E-mail: isabela.pborges@gmail.com.

**** PhD student in Genetics and Biochemistry, Federal University of Uberlândia, State of Minas Gerais, Brazil. E-mail: deborahfcp@gmail.com.
} 


\section{Introdução}

Unidades de Conservação (UCs) são áreas do território nacional instituídas pelo poder público e destinadas à proteção de ecossistemas significativos, sendo um dos seus objetivos gerais a condução de atividades de Educação Ambiental (EA), as quais visam desenvolver uma consciência pública voltada para a conservação do meio ambiente e dos recursos naturais (BRASIL, 2000).

Os parques urbanos como UCs apresentam diversas atividades desenvolvidas a partir da implementação de programas de EA, tais como: visitação por estudantes e professores, criação de materiais educativos, criação de exposições, realização de campanhas educativas, recepção de visitantes, entre outros. Os projetos de EA envolvendo UCs têm atingido um público bastante heterogêneo. Para a priorização de um grupo social, devese considerar os problemas específicos de cada UC, os recursos disponíveis, o poder de tomada de decisão e a importância do grupo social para a manutenção desses locais (MAROTI, 2002). Sendo assim, esses projetos são geridos pelos Centros de Educação Ambiental (CEAs), como os Núcleos de Educação Ambiental (NEAs), e apoiados, em sua maioria, pelo setor público.

Na cidade de Uberlândia, Minas Gerais, Brasil, o Parque Victório Siquierolli é um dos parques que possui NEA e se enquadra na categoria de Unidade de Conservação de Proteção Integral. A criação do Parque foi motivada por uma preocupação por parte do antigo proprietário (PARQUE, 2000), e o aumento das ocupações dos bairros adjacentes, a partir de 1970, intensificou mais ainda a preocupação em se criar uma reserva que abrangesse e preservasse a vegetação local (RAMIRES; FREITAS, 1995).

A sede do parque é composta pelo espaço administrativo, Conselho Municipal de Desenvolvimento do Meio Ambiente
(CODEMA), Museu de Biodiversidade do Cerrado e pela Sala Verde Dr. Kerr. Existe também um parque infantil, pista para caminhada e trilhas interpretativas que visam o conhecimento do parque e o incentivo à EA. O Parque tem como objetivos a conscientização da necessidade de preservação da área, que é constituída por uma vegetação de cerrado típico (COIMBRA; OLIVEIRA, 2009), o incentivo de programas de manejo voltados para a conservação de recursos naturais e o uso sustentável pela sociedade, além de oferecer subsídios a pesquisas científicas e educação ambiental (MUSEU, 2011). O público mais frequente, durante a semana, são estudantes, principalmente de escolas públicas e de nível fundamental. Aos finais de semana, ocorre visitação de um público variado, desde crianças até idosos, geralmente dos bairros ao redor, principalmente, como uma forma de lazer.

Tendo em vista o cenário atual, marcado pela degradação permanente do meio ambiente, principalmente do Cerrado, é necessária uma reflexão sobre as práticas sociais relacionadas com a produção de conceitos sobre a EA. Para essa educação obter bons resultados, é preciso, primeiramente, potencializar o envolvimento dos sistemas de compartilhamento de conhecimento, como os professores e até mesmo os universitários em um âmbito interdisciplinar. É fundamental reformular a EA, para que seja realizada de maneira formalizada ou não, ou seja, tanto em salas de aula como em parques e museus, relacionando o homem e a natureza (JACOBI, 2002). A EA deve ser um conjunto de práticas pedagógicas voltadas para a conscientização, desenvolvimento de competências e mudanças comportamentais dos educandos (REIGOTA, 1998) e deve propiciar condições básicas para estimular maior integração e harmonia dos indivíduos com o meio ambiente (PÁDUA; TABANEZ, 1998). 
Visto que está cada vez mais desafiadora a relação entre meio ambiente e educação, é necessário rever os processos de EA em parques e escolas para a formação e conscientização das atuais e novas gerações (JACOBI, 2002), formando cidadãos mais críticos e preocupados com o meio em que vivem.

Analisando o NEA do Parque Victório Siquierolli, segundo Coimbra e Oliveira (2009), percebemos que ele é formado por um espaço físico e um ambiente de trabalho adequado para a implementação das atividades de EA, servindo, ainda, como um apoio às atividades de pesquisa e extensão. Ao desenvolver atividades com alunos e professores, bem como atividades abertas à comunidade, o NEA pode desempenhar o papel de prestação de serviços. Além disso, mesmo que as condições estruturais do NEA do Parque Siquierolli não sejam as ideais, comparativamente aos demais centros espalhados pelo país, o NEA do Parque tem atendidosatisfatoriamentea comunidadeescolar, pesquisadores e a comunidade como um todo.

O presente estudo, portanto, teve como objetivo a elaboração, o desenvolvimento e a avaliação de um plano pedagógico para estudantes de ensino fundamental para o Parque Victório Siquierolli, com caráter inovador e com o intuito de sensibilizar as novas gerações quanto às noções de preservação do meio ambiente e conservação de recursos naturais, já que o NEA do Parque não apresenta, de forma sistematizada, um plano pedagógico (COIMBRA; OLIVEIRA,
2009). Vale ressaltar que esse trabalho não procura apenas mostrar que as UCs são locais de conservação e lazer, mas também que esses espaços representam excelentes ambientes de ensino-aprendizagem, interferindo diretamente na formação e na aprendizagem significativa de alunos e professores.

\section{Metodología}

O estudo foi realizado em parceria com a Escola Estadual Jardim Ipanema, com a participação de 47 alunos do $9^{\circ}$ ano, os quais participaram de uma visita ao Parque Victório Siquierolli no primeiro semestre de 2012. Primeiramente, foi aplicado um questionário (Quadro 1) aos alunos e professores envolvidos para obter informações prévias a respeito: do entendimento dos alunos quanto à EA; do aproveitamento, por parte dos alunos e professores, das atividades realizadas atualmente no parque; das deficiências das atividades de EA no parque. Com base nas respostas, elaborou-se um plano pedagógico, que atendia as necessidades e expectativas dos estudantes. Esse plano foi aplicado no dia da visita ao parque para obter um feedback e analisar se o plano pedagógico atendia ao objetivo proposto. Esse feedback foi obtido a partir de questões feitas aos alunos e aos professores após a visita (Quadro 2), além de observações e anotações feitas pelos autores desse artigo durante a visita. 
Quadro 1 - Questionário prévio aos alunos e professores.

\begin{tabular}{|l|l|}
\hline \multicolumn{1}{|c|}{ Alunos } & \multicolumn{1}{c|}{ Professores } \\
\hline 1 - Para você, o que é Educação Ambiental? & $\begin{array}{l}1 \text { - Você acha que o parque oferece uma estrutura e } \\
\text { recursos ideais para visitação? }\end{array}$ \\
\hline $\begin{array}{l}2-\text { Quais tipos de atividades você espera } \\
\text { encontrar no parque? }\end{array}$ & 2 - Qual o objetivo da visita ao parque? \\
\hline $\begin{array}{l}3-\text { O que seria possível aprender com as } \\
\text { atividades citadas na questão anterior? }\end{array}$ & $\begin{array}{l}3 \text { - Foi realizada uma explicação prévia aos alunos } \\
\text { sobre Educação Ambiental e as atividades a serem } \\
\text { realizadas no parque? }\end{array}$ \\
\hline
\end{tabular}

Fonte: Os autores (2017).

Quadro 2 - Questionário posterior aos alunos e professores.

\begin{tabular}{|l|l|}
\hline \multicolumn{1}{|c|}{ Alunos } & \multicolumn{1}{|c|}{ Professores } \\
\hline $\begin{array}{l}1-\text { As atividades realizadas no parque } \\
\text { corresponderam às suas expectativas? Justifique. }\end{array}$ & $\begin{array}{l}2-\text { O plano de Educação Ambiental desenvolvido na } \\
\text { visita poderia ser adotado pelo parque? Justifique. }\end{array}$ \\
\hline
\end{tabular}

Fonte: Os autores (2017).

O plano pedagógico foi montado para melhor atender aos alunos, sem desrespeitar os objetivos que a escola e os professores tinham com a visita. A intenção do plano era integrar as atividades do parque com o conhecimento prévio dos alunos e o conhecimento que iriam adquirir durante a visita ao parque. O plano apresentava três atividades:

\section{$1^{a}$ Atividade: Socialização dos saberes}

Essa atividade procurou ampliar, especialmente, o conhecimento dos alunos e fornecer subsídios para as outras atividades. Primeiramente, os alunos fizeram uma visita ao Museu de Biodiversidade, onde havia espécies de animais empalhados. Após essa visita, os alunos foram reunidos e divididos em cinco grupos: Grupo 1 - Vegetal e Mamífero; Grupo 2 Vegetal e Ave; Grupo 3 - Vegetal e Peixe; Grupo 4 - Vegetal e Inseto; e Grupo 5 - Vegetal e Réptil.
Após essa divisão, os alunos foram conduzidos à "Trilha do Óleo" (atividade oferecida no parque), juntamente com um instrutor que trabalha no local. Durante a trilha, os alunos receberam informações sobre o bioma Cerrado, como: a importância e as consequências do fogo para o bioma; por qual motivo as árvores deste ambiente têm características tortuosas; a utilidade de algumas espécies, como o óleo de Copaíba (Copaifera langsdorfii) que é usado para fins medicinais e cosméticos e constitui um item de exportação do Brasil; dentre outras informações. Após passarem por essa trilha, cada grupo deveria escolher um vegetal e um animal que achassem interessante, anotar suas características e escrever qual a sua importância no meio ambiente. Para isso, os cinco grupos foram reunidos em um local aberto e tiveram de 15 a 20 minutos para elaborarem as respostas. 


\section{2ªtividade: Problemática}

Após terem completado a 1a Atividade e utilizando as espécies de animais e plantas escolhidas, colocou-se uma problemática para cada grupo:

Grupo 1 - A espécie de árvore escolhida estava sendo desmatada. O que eles poderiam fazer quanto a esse problema? O mamífero escolhido pelo grupo estava sendo caçado ilegalmente, apenas por diversão. O que o grupo poderia propor para que isso não acontecesse?

Grupo 2 - A espécie de árvore escolhida estava sendo ameaçada de extinção pela grande quantidade de incêndios. O que eles poderiam fazer para evitar esse problema? A ave escolhida pelo grupo estava sendo contrabandeada. O que o grupo poderia propor para que isso não acontecesse? Grupo 3 - O solo do local onde se encontrava a espécie de árvore escolhida estava sendo usado como "lixão" (área de descarte de lixo). O que eles poderiam fazer para evitar tal problema? O peixe escolhido pelo grupo estava em um rio muito poluído e estava morrendo. O que o grupo poderia propor para que isso não acontecesse?

Grupo 4 - O lençol freático do local onde se encontrava a espécie de árvore escolhida estava sendo contaminado por produtos tóxicos, os quais eram descartados ilegalmente por uma fábrica. O que eles poderiam fazer para evitar esse problema? O inseto escolhido pelo grupo era responsável pela polinização de várias árvores, mas estava morrendo devido ao elevado uso de agrotóxicos. O que o grupo poderia propor para que isso não acontecesse?

Grupo 5 - Na floresta onde se encontrava a espécie de árvore escolhida estavam sendo introduzidas, ilegalmente, algumas espécies de plantas exóticas que induziam a diminuição das espécies de árvores nativas. O que eles poderiam fazer para evitartal diminuição? O réptil escolhido pelo grupo estava sendo caçado para o uso da pele na confecção de roupas. O que o grupo poderia propor para que isso não acontecesse?

Os grupos tiveram de 15 a 20 minutos para resolverem o problema e falar as respectivas soluções para os demais grupos.

\section{$3^{a}$ Atividade: Reflexão}

A terceira atividade consistiu em um momento de reflexão entre os grupos: professores, instrutores e monitores participaram desse momento para conversar, discutir e refletir sobre os problemas e as soluções existentes para um melhor funcionamento do ecossistema e para uma melhor preservação do meio ambiente. Nesse momento, os alunos deveriam aprender com essa atividade que cada ser vivo apresenta uma importância para natureza, seja ele animal ou vegetal, e que existem problemas ambientais, muitas vezes provocados pelo homem, que podem ser resolvidos com a conscientização (sensibilização), atitude e a ação de cada um, lutando para defender o meio ambiente.

\section{Resultados e Discussão}

Após a aplicação do questionário prévio, constatou-se, com uma representatividade de $74 \%$, que a atividade que os alunos mais esperavam realizar no parque foi uma "gincana", seguida por "visita a mata fechada" e "ver animais", com uma representatividade de $21 \%$ e 5\%, respectivamente (Figura 1). Resultado semelhante foi encontrado por Cursino (2010) ao desenvolver um projeto de Educação Ambiental (EA) com uma comunidade ribeirinha no estado de São Paulo, que sofria com problemas de impermeabilização de recursos hídricos, enchentes e despejo de dejetos em córregos e terrenos baldios. Nesse trabalho, a autora propôs e apresentou resultados positivos após desenvolver uma gincana com a comunidade. A proposta de gincana favorece a relação 
das crianças com os adultos, possibilitando a realização de atividades como jogos, desenhos, atividades criativas em geral, as quais, além de serem prazerosas, contribuem para o desenvolvimento das capacidades humanas das crianças (HURTADO, 2001).

Figura 1 - Expectativa dos alunos de 9o ano sobre quais atividades seriam realizadas durante a visita ao parque.

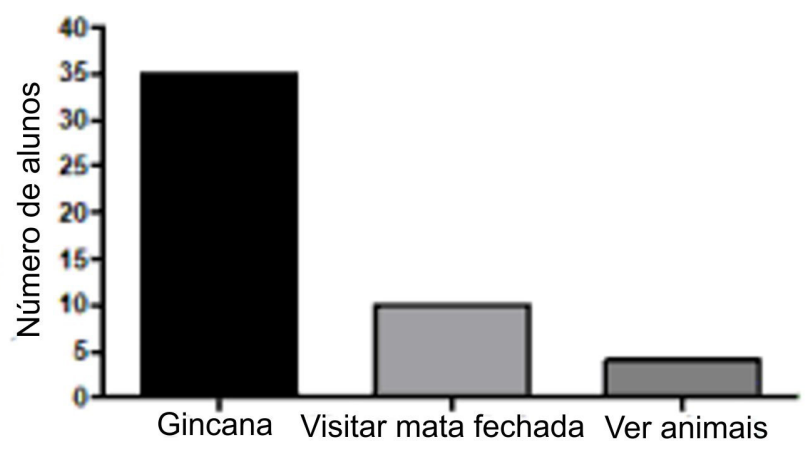

Fonte: Os autores (2017).

Durante a visita ao parque, a primeira atividade realizada foi a visita ao Museu de Biodiversidade do Cerrado, no qual os alunos observaram os animais característicos do bioma, mas sem muito interesse (observações pessoais). Logo após a visita, os alunos foram divididos em grupos e receberam as perguntas da atividade que foi proposta. Assim, voltaram ao Museu demonstrando mais entusiasmo e interesse, o que mostra que se os alunos têm que responder a questões ou ser avaliados dedicam-se mais em entender o conteúdo, o que pode favorecer um melhor processo de ensino-aprendizagem.

Posteriormente, os alunos conheceram a Trilha do Óleo, onde notou-se que houve grande interação com a atividade proposta e a explicação fornecida por um funcionário do Parque a respeito da vegetação encontrada na trilha, o que facilitou aos alunos resolverem os problemas da atividade. Alguns trabalhos levantam a eficácia do uso de trilhas interpretativas em UCs nas questões referentes, especificamente, à EA para o ensino médio e fundamental (SENICIATO, 2002). Carvalho (2004) acrescenta que além de apresentar algumas características da vegetação, solo e microclima, as trilhas sensibilizam os alunos para os problemas decorrentes das atividades antrópicas, presente na Trilha do Óleo por meio da observação dos processos erosivos e poluição do Córrego Liso (córrego que passa dentro do Parque), o que supera o caráter apenas explicativo e constitui uma excelente técnica de sensibilização aos problemas ambientais apresentados na região. Após a trilha e a visita ao Museu, os alunos se reuniram em uma área aberta para discutirem e refletirem sobre os problemas resolvidos. Eles se mostraram bastante dedicados ao apresentarem suas soluções para os problemas e houve uma grande interação por parte dos outros grupos, que questionavam e ouviam as respostas com atenção.

Notou-se que os alunos se empenharam para realizar a atividade e discutiram diversos pontos importantes acerca do conteúdo, o que sugere uma aprendizagem significativa por parte deles. Observou-se também um "espírito competitivo" entre os alunos ao buscarem 
as melhores soluções para os problemas propostos. Esse processo competitivo, muitas vezes, é importante para o processo de ensinoaprendizagem, pois desperta a atenção, a criatividade e a participação dos alunos. Além desse fator competitivo, o local de estudo é outro ponto relevante no processo de ensinoaprendizagem, que, no presente trabalho, era informal, onde os alunos podiam sentar no chão e tinham mais contato com a natureza, bem diferente da sala de aula, que representa um local, em sua maioria, com baixo contato com o meio ambiente e aparenta ter uma obrigatoriedade de acerto de respostas. Essas atividades diversas e diferenciadas permitem instigar os estudantes à construção do senso crítico, relacionando ideias do senso comum com os conceitos científicos (MORIN, 2003; VIEIRA; BIANCONI; DIAS, 2005).
Tomando como base a $2^{\underline{a}}$ atividade proposta e os dois questionários aplicados aos alunos, foram encontradas quatro principais ações de preservação do meio ambiente: conservação dos animais, conservação das plantas, como não poluir a água e como não poluir o solo (Figura 2). Além disso, no questionário, 96\% das expectativas dos alunos foram alcançadas, mesmo sem explicação prévia sobre o conteúdo abordado na visita ao parque pela maioria dos professores em sala de aula. Os professores, por sua vez, também se mostraram satisfeitos com o resultado da atividade, ao responderem o questionário aplicado posteriormente à visita, no qual a maioria opinou que o plano de EA proposto neste trabalho pode ser adotado pelo Parque em razão dos alunos poderem entender melhor os problemas relacionados ao meio ambiente.

Figura 2 - Principais ações de preservação do meio ambiente encontradas nas respostas dos alunos de 9 응 ano.

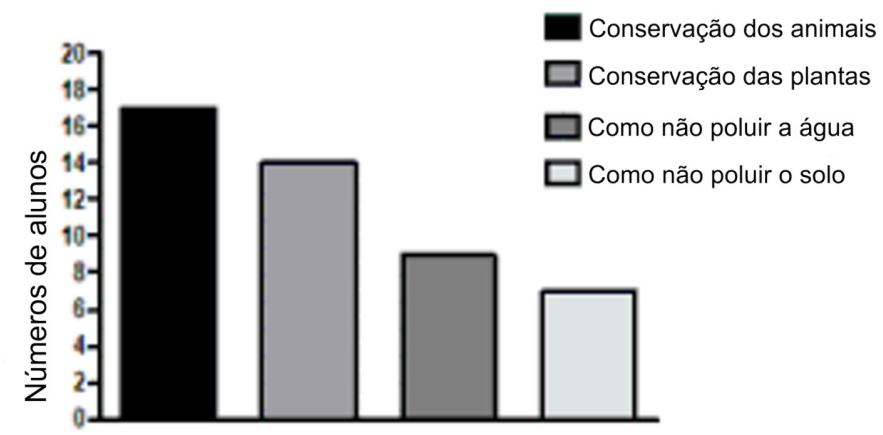

Fonte: Os autores (2017).

Dentro desse contexto, percebe-se que as UCs, como é o caso do Parque Municipal Victório Siquierolli, são ambientes propícios e ideais para a construção e implementação de atividades relacionadas à EA, abordando temas como: uso e manejo de solos e de fauna e flora em ambientes preservados, ocupação do homem versus preservação, conservação de recursos naturais, dentre outros. A EA, que ocorre geralmente nas UCs, é aquela que trabalha com conceitos e abordagens ecológicas. Dentro dessa visão, destaca-se o estudo feito por Seniciato (2002). A autora coloca que o recurso da aula de campo nos ecossistemas naturais 
possibilita aos alunos observarem os fenômenos da maneira como ocorrem na natureza, além de favorecer o relacionamento dos alunos com os fatores bióticos e abióticos que interagem nestes ambientes. Assim, as UCs são importantes para as atividades de EA e percepção dos alunos em relação aos ecossistemas, independentemente da disciplina escolar.

De uma forma geral, o plano pedagógico proposto trabalhou com três vertentes importantes no processo de ensinoaprendizagem: Socialização dos saberes nessa etapa ocorre o compartilhamento de saberes entre alunos e professores a partir do conhecimento prévio de cada um, colocando o processo de ensino-aprendizagem em primeiro plano; Problemática - nessa etapa, questões e problemas são levantados, buscando alcançar os exemplos mais próximos da realidade dos estudantes e procurando fomentar o raciocínio destes para a preocupação e resolução de tais problemas; e Reflexão - nessa etapa, buscase integrar o maior número de informações possíveis com o intuito de rever determinadas ações e agir de forma diferente, pelo menos em relação ao meio em que vivemos. O Quadro 3 mostra melhor como o plano pedagógico desenvolvido nesse estudo funciona.

Quadro 3 - Caracterização das etapas do plano pedagógico proposto como alternativa para o ensino de Educação Ambiental no Parque Victório Siquierolli.

\begin{tabular}{|l|l|l|}
\hline Socialização dos saberes & Problemática & Reflexão \\
\hline Conhecimentos adquiridos por & Levantamento de questões & Utilização de todas as \\
qualquer meio ou fonte; forma & relacionadas a determinado & informações possíveis para \\
empírica (ex.: escola, museus, & contexto (meio ambiente, & repensar determinadas ações \\
internet, televisão, parques, entre & crescimento populacional, & e, futuramente, agir de forma \\
outros). & economia, política, entre outros). & diferente. \\
\hline
\end{tabular}

Fonte: Os autores (2017).

\section{Considerações finais}

A EA tem alcançado uma maior visibilidade, principalmente dentro das UCs. Estudos mais aprofundados relacionados com projetos pedagógicos, planos de aula e métodos didáticos utilizando parques para a aplicação da EA, e consequente sensibilização do público com relação as questões ambientais, são cada vez mais necessários.

A introdução da EA no processo de ensino-aprendizagem por meio de projetos ou planos pedagógicos, como o elaborado nesse estudo, oferecem aos participantes, principalmente alunos de ensino fundamental e médio, uma socialização de conhecimentos e a conscientização das questões relacionadas ao meio ambiente. Observou-se, portanto, que com o plano pedagógico elaborado e um breve embasamento teórico envolvido, os alunos discutiram diversos pontos relacionados às questões ambientes de uma forma mais ativa, mostrando que esse projeto pode ser aplicado no Parque Municipal Victório Siquierolli, bem como em diversos outros parques e UCs, como um instrumento de EA. 


\section{Referências}

BRASIL. Ministério da Educação. Lei Federal no 9.985, de 18 de junho de 2000. Regulamenta o artigo 225, § 10, incisos I, II, III e VII da Constituição Federal, institui o Sistema Nacional de Unidades de Conservação. 2000. Disponível em: < https://www.planalto.gov. br/ccivil_03/Leis/L9985.htm>. Acesso em: 26 abr. 2015.

CARVALHO, I. C. M. Educação ambiental: a formação do sujeito ecológico. São Paulo: Cortez, 2004. 256 p.

COIMBRA, F. G.; OlIVEIRA, A. M. C. de. Parque Municipal Victório Siquierolli: um novo olhar sobre educação ambiental. Caminhos de Geografia, Uberlândia, v. 10, n. 31, p. 135-146, p. 135146, 2009.

CURSINO, A. R. Gincana como instrumento de educação ambiental aplicada em uma escola de São José dos Campos, São Paulo. In: SIMPÓSIO DA ENGENHARIA AMBIENTAL, 6., 2010, Presidente Prudente. Anais... Presidente Prudente: UNESP, 2010.

HURTADO, J. L. Un nuevo concepto de educación infantil. Havana: Editorial Pueblo y educación, 2001. 30 p.

JACOBI, P. Educação ambiental, cidadania e sustentabilidade. Cadernos de Pesquisa, São Paulo, v. 118, p. 189-205, 2002.

MAROTI, P. S. Educação e interpretação ambiental junto à comunidade do entorno de uma unidade de conservação. 2002. 118 f. Tese (Doutorado em Ecologia e Recursos Naturais) Universidade Federal de São Carlos, São Paulo, 2002.

MORIN, E. A cabeça bem-feita: repensar a reforma, reformar o pensamento. 8. ed. Rio de Janeiro: Bertrand Brasil, 2003. 128 p.

MUSEU de Biodiversidade do Cerrado. Parque Municipal Victório Siquierolli. Disponível em: <http://www.mbc.ib.ufu.br/node/42>. Acesso em: 27 abr. 2017.

PÁDUA, S. M.; TABANEZ, M. F. Educação ambiental: caminhos trilhados no Brasil. São Paulo: Ipê, 1998. $286 \mathrm{p}$.

PARQUE Municipal Victório Siquierolli. Meio ambiente e desenvolvimento urbanístico. Disponível em: <http://www.uberlandia.mg.gov.br/2014/secretaria-pagina/51/138/secretaria.html>. Acesso em: 3 maio 2017.

RAMIRES, J. C.; FREITAS, C. M. de. Agentes sociais e produção do espaço urbano: a estruturação do Distrito Industrial de Uberlândia. Sociedade e Natureza, Uberlândia, v. 7, n. 13, p. 49-68, jan.dez. 1995.

REIGOTA, M. Desafios à educação ambiental escolar. In: CASCINO, F.; JACOBI, P.; OLIVEIRA, J. F. (Orgs.). Educação, meio ambiente e cidadania: reflexões e experiências. São Paulo: SMA/CEAM, 1998. p. 43-52. 
SENICIATO, T. Ecossistemas terrestres naturais como ambientes para as atividades de ensino de Ciências. 2002. 138 f. Dissertação (Mestrado em Educação para a Ciência) - Faculdade de Ciências, Universidade Estadual Paulista, Bauru, 2002.

VIEIRA, V.; BIANCONI, M. L.; DIAS, M. Espaços não formais de ensino e o currículo de ciências. Ciência e Cultura, São Paulo, v. 57, n. 4, p. 21-23, out.-dez. 2005.

Submetido em 15 de agosto de 2017.

Aprovado em 15 de outubro de 2017. 